\title{
A incidencia de reescrituras fílmicas na relación de nomeados e premiados dos principais galardóns internacionais a longametraxes animadas
}

\author{
Rocío G-Pedreira \\ CIEC-IE-Universidade do Minho/ \\ ICE-Universidade de Santiago de Compostela \\ https://orcid.org/0000-0002-5102-5078 \\ [Recibido, 23 abril 2020; aceptado, 4 xuño 2020]
}

[G-Pedreira, R. (2020). A incidencia de reescrituras fílmicas na relación de nomeados e premiados dos principais galardóns internacionais a longametraxes animadas. Boletín Galego de Literatura, 56, "Estudos", 23-40]

DOI http://dx.doi.org/10.15304/bgl.56.6776

RESUMO O presente artigo pretende dar conta da presenza de reescrituras fílmicas de obras literarias realizadas mediante técnicas de animación cuxa calidade as fixo merecedoras de ser nomeadas e/ou premiadas con algúns dos galardóns cinematográficos a nivel mundial máis importantes que contan cunha categoría específica para estas producións, en concreto os Óscar, Annie, Globos de Ouro e BAFTA. Ademais, tamén se analizará brevemente a influencia que ten a creación do hipertexto fílmico para a difusión do correspondente hipotexto.

PALABRAS CHAVE Premios cinematográficos; cine de animación; reescrituras fílmicas; adaptación.

ABSTRACT This article aims to report about the presence of film rewritings of literary works through animation techniques whose quality making them deserving of being nominees and/ or designed to award some of the most important film awards around the world with a specific category for animated films, in particular, the Oscars, Annie Awards, Golden Globes and BAFTA. Furthermore, it will be analysed briefly the influence of the creation of the film hypertext for hypotext diffusion.

KEYwORDS Film Awards; animation cinema; film rewriting; adaptation.

\section{Introdución}

Un dos aspectos máis distintivos do cinema é a súa existencia como arte, oficio, industria e cultura. Pese ás dificultades que se atoparon no camiño, as películas son consideradas en maior ou menor medida producións artísticas de signo estético inmersas nun sistema cultural concreto no que arraigan e 
co cal dialogan, influíndose mutuamente; non obstante, tamén se trata dunha industria que move a miles de traballadores e cantidades considerables de diñeiro, cuxos perfiles profesionais son altamente especializados e diversos, dende directores a guionistas, produtores, deseñadores, operadores etc. Neste senso, o financiamento vólvese un aspecto determinante para a posibilidade de creación destas obras que, ademais, está directamente influído polo que acaden durante a súa proxección nos cines ou a súa difusión en medios como a televisión ou os servizos de streaming, entre outros.

$\mathrm{Na}$ busca dunha posición privilexiada dentro do sistema correspondente, os premios cinematográficos actúan como unha estratexia de mercadotecnia que revitaliza a incidencia dunha película. Un claro exemplo sería a reaparición na carteleira de películas xa estreadas logo da consecución dun galardón salientable ou a inclusión deste distintivo a xeito de paratexto verbal ${ }^{1}$ no cartel publicitario ou outros elementos de difusión.

O presente artigo comeza cunha pequena reflexión sobre a importancia dos premios cinematográficos no asentamento dunha obra dentro dos subcampos da gran produción e da produción restrinxida ${ }^{2}$ e, no caso concreto de hipertextos fílmicos, farase referencia ás consecuencias que teñen tamén para a permanencia e supervivencia do hipotexto literario no imaxinario colectivo. A continuación, investigarase sobre a incidencia de reescrituras cinematográficas dentro das listas de nomeados de varios certames relevantes a nivel internacional con categorías específicas para as longametraxes animadas,

1 Gérard Genette (1987) explica que o paratexto trátase de aquilo polo cal un texto se fai libro e se propón como tal aos seus lectores. Componse empiricamente dun conxunto variado de prácticas e discursos que se modifican continuamente en función das épocas, culturas, xéneros, autores, obras etc. A partir do seu emprazamento fala de dous tipos: peritextos, aqueles que se sitúan arredor do texto, no espazo do volume, ou inclusive nos intersticios do texto; e epitextos, que tamén se atopan arredor do texto, pero a unha distancia máis prudente, no exterior do texto, e que tenden a utilizarse como soporte mediático ou baixo a forma dunha comunicación privada.

2 Os conceptos arredor do campo literario foron introducidos por Pierre Bourdiev e, segundo o Dicionario de Termos Literarios (DiTerLi) do Equipo Glifo (http://bernal.cirp.gal/ords/f? p=106:1 ::::::), configúrase como un marco de loitas encamiñadas a transformar ou conservar a relación de forza existente ou estado do campo. Nos campos, culturais, entre eles o literario, sitúanse os autores ou produtores, mentres os consumidores están no campo do poder, no que prevalece o capital económico. Polo tanto, a estrutura do campo literario depende do grao de autonomía que manteñan con respecto ao campo de poder, podendo delimitar dous subcampos: o de gran produción, que goza de pouca autonomía ao se guiar polo beneficio económico que articula o campo de poder, de xeito que os produtores se miden polo éxito comercial e a notoriedade social; e o campo de produción restrinxida, que mostra polo contrario un alto grao de autonomía con respecto ao campo de poder. Este ultimo caso dá a posibilidade de darlle ás obras prestixio e lexitimidade artística. 
facendo fincapé nas premiadas, das cales se identificarán as súas principais sinais de identidade, como a tipoloxía da técnica de animación utilizada ou o tipo de reescritura do que se trata.

\section{A importancia dos premios cinematográficos}

No artigo inicial do monográfico Premios literarios e de ilustración na LIX (2013), escrito por Anxo Tarrío, o autor fai unha achega teórica ao fenómeno dos premios literarios onde afirma que se constitúen como unha das estratexias máis gorentosas e rápidas de conseguir unha posición privilexiada no campo literario e, á súa vez, no campo de poder. Ademais, tamén especifica que a instalación no subcampo da gran produción (o que se rexe pola demanda externa e no que a primacía se mide polo número de exemplares vendidos) ou no da produción restrinxida (a procura do beneficio económico queda excluída ou minorizada e, en consecuencia, os produtores manteñen unha forte independencia respecto da demanda maioritaria) depende das características intrínsecas do premio en cuestión.

Calquera que sexa o caso, unha das conclusións máis salientables do artigo de Tarrío (2013, p. 30) é "a consideración dos premios literarios como elementos fundamentais do mercado en que se converteu a literatura durante o século XX". Así, a canonización e lexitimación dun autor, xénero, título ou tendencia é especialmente sensíbel da consecución dun galardón de calquera tipo que leve implícito un valor económico ou calquera outro con peso específico de seu. No caso das obras cinematográficas, os premios outorgados en cadanseu evento ou cerimonia correspondente funcionan máis como un elemento para o aumento do recoñecemento e difusión das producións, que na súa creación previa xa necesitou dunha cantidade de diñeiro substancial en comparación co caso doutras obras artísticas como as literarias, pero que tamén posibilitan un aumento considerábel dos beneficios. A produción dunha película ten un gasto económico elevado polos recursos técnicos, materiais e humanos necesarios. Se nos fixamos no caso concreto da industria cinematográfica norteamericana, a máis potente do mundo, a súa maior fortaleza é a madureza financeira. A súa capacidade é moito máis grande que a doutros territorios e o cine funciona como un produto financeiro de risco máis. Así, un inversor pode perdelo todo se unha produción non funciona. No caso español e, en certa medida, no de toda a industria audiovisual europea, o fi- 
nanciamento para a realización de películas estivo directamente relacionado coas subvencións. No artigo de Miguel Ángel Poveda Criado (2015) sobre as fontes de financiamento da industria audiovisual española, perfila tres razóns fundamentais que explican esta realidade: trátase dun sector de risco, pois as posibilidades de que unha produción teña éxito ou que polo menos recupera a inversión son moi incertas; considérase máis unha manifestación cultural que unha industria en sentido estrito; e o feito de que a consecución dunha subvención é, a miúdo, a única maneira de producir ou comercializar unha película debido ao seu escaso interese comercial ou ás dificultades na distribución.

En efecto, as fontes de financiamento poden ser públicas, como axudas, subvencións e incentivos fiscais, ou privadas, como as preventas especiais (bandas sonoras, mercadotecnia, patrocinios...), as ventas de emisión ou os préstamos bancarios. O tipo de produción determina en certa medida o tipo de financiamento e, no caso concreto das películas de animación infantís e/ ou familiares, cobra especial importancia a mercadotecnia dos produtos derivados delas. Un claro exemplo deste fenómeno a gran escala sería todo o artificio que Disney-Pixar leva a cabo con cada nova estrea, sacando á venta figuras, novelas gráficas, contos, cadernos de pintar ou de adhesivos, roupa, bonecos etc. Ademais, no caso de reescrituras fílmicas, en moitos casos aprovéitase a ocasión para reeditar os libros no que se basean. Este último aspecto trátase dun dos moitos beneficios que pode traer a realización dunha película para as ventas dun libro cando se trata dunha reescritura cinematográfica e, por suposto, se se autoidentifica a si mesma como tal.

No caso das obras cinematográficas realizadas mediante técnicas de animación, a inclusión de categorías específicas para elas foi un paso decisivo na consolidación do que se considerou, durante moito tempo, unha modalidade xenérica en si mesma relacionada co público infantil e coas producións edulcoradas, artificiosas e banais, no lugar de darlle a consideración de técnica ou forma de facer cine que lle corresponde. Non obstante, como resalta Jayne Pilling nun artigo titulado "La animación se hace mayor" (2013), o mercado mainstream (tendencia ou corrente maioritaria) da animación segue sendo o público infantil/familiar. Por esta razón, os hipotextos literarios de moitas das reescrituras cinematográficas que se irán mencionando ao longo do estudo pertencen ao sistema literario infantil e xuvenil. 


\section{A incidencia de reescrituras cinematográficas nos galardóns a longametraxes animadas}

Resulta evidente que un dos valores máis importantes dos premios é a capacidade comunicativa e relevancia que lle ofrecen a unha película. O artigo de Eva Deuchert, Kossi Adjamah e Florian Pauly (2005) sobre o impacto do nomeamento e a consecución dos premios Óscar afirman que estes galardóns afectan directamente na toma de decisións por parte dos espectadores de ver ou non unha película. Ademais, conclúen que este aumento do recoñecemento e difusión dos filmes afecta a todos os nomeados, non só aos gañadores.

Precisamente os Óscar son un dos catro galardóns seleccionados para a análise que compoñen estas liñas, ademais dos BAFTA, Annie e os Globos de Ouro. As razóns da escolla foron a súa notoriedade e importancia, así como a existencia dunha categoría específica para o caso das longametraxes animadas. A continuación introdúcese brevemente cada premio e unha relación dos distintos nomeados e gañadores de cada ano, seguindo a seguinte lenda de cores para destacar as producións de especial interese para o estudo:

Reescritura de narrativas infantís, xuvenís ou de adultos (contos, álbums ilustrados, novelas)

Reescritura de banda deseñada (novela gráficas, tiras cómicas ou manga)

- Premios Óscar: considerados os máis importantes e recoñecidos do mundo, trátase duns premios anuais concedidos pola Academia das Artes e das Ciencias Cinematográficas con sede nos Ánxeles, California. A categoría de Óscar á mellor película de animación foi creada no 2002, e a primeira película gañadora foi Shrek (2002). Non obstante, no 1938 e no 1995 concedéronse premios especiais a dúas películas de animación, Snow White and the Seven Dwarfs (1937) e Toy Story (1995) respectivamente. No seguinte cadro é posible rastrear os distintos filmes nomea$\operatorname{dos}^{3}$, indicando tamén os países de procedencia e a dirección das obras gañadoras:

3 En todos os casos respectarase o título orixinal da película, agás no caso das producións xaponesas, para as cales se utilizará a tradución ao español utilizada na súa estrea a nivel nacional. 


\begin{tabular}{|c|c|c|c|c|}
\hline $\begin{array}{l}\text { Edición/ } \\
\text { Ano }\end{array}$ & Película & Director & País & Nomeadas \\
\hline $\begin{array}{l}74^{\circ} \\
2001\end{array}$ & Shrek & $\begin{array}{c}\text { Andrew } \\
\text { Adamson, Vicky } \\
\text { Jenson }\end{array}$ & $\begin{array}{l}\text { Estados } \\
\text { Unidos }\end{array}$ & $\begin{array}{l}\text { Jimmy Neutron: Boy Genius } \\
\text { (Estados Unidos) } \\
\text { Monsters, Inc. (Estados Unidos) }\end{array}$ \\
\hline $\begin{array}{l}75^{\circ} \\
2002\end{array}$ & $\begin{array}{l}\text { El viaje de } \\
\text { Chihiro }\end{array}$ & Hayao Miyazaki & Xapón & $\begin{array}{l}\text { Ice Age (Estados Unidos) } \\
\text { Lilo \& Stitch (Estados Unidos) } \\
\text { Spirit: Stallion of the Cimarron } \\
\text { (Estados Unidos) } \\
\text { Tresaure Planet (Estados Unidos) }\end{array}$ \\
\hline $\begin{array}{l}76^{\circ} \\
2003\end{array}$ & Finding Nemo & Andrew Stanton & $\begin{array}{l}\text { Estados } \\
\text { Unidos }\end{array}$ & $\begin{array}{l}\text { Brother Bear (Estados Unidos) } \\
\text { Les Triplettes de Belleville (Francia, } \\
\text { Bélxica, Canadá, Reino Unido) }\end{array}$ \\
\hline $\begin{array}{c}77^{\circ} \\
2004\end{array}$ & The Incredibles & Brad Bird & $\begin{array}{l}\text { Estados } \\
\text { Unidos }\end{array}$ & $\begin{array}{l}\text { Shark Tale (Estados Unidos) } \\
\text { Shrek } 2 \text { (Estados Unidos) }\end{array}$ \\
\hline $\begin{array}{l}78^{\circ} \\
2005\end{array}$ & $\begin{array}{l}\text { Wallace \& } \\
\text { Gromit: The } \\
\text { Curse of the } \\
\text { Were-Rabbit }\end{array}$ & $\begin{array}{l}\text { Nick Park, Steve } \\
\text { Box }\end{array}$ & Reino Unido & $\begin{array}{c}\text { Corpse Bride (Reino Unido, Estados } \\
\text { Unidos) } \\
\text { El castillo ambulante de Howl } \\
\text { (Xapón) }\end{array}$ \\
\hline $\begin{array}{l}79^{\circ} \\
2006\end{array}$ & Happy Feet & George Miller & $\begin{array}{l}\text { Australia, } \\
\text { Estados } \\
\text { Unidos }\end{array}$ & $\begin{array}{c}\text { Cars (Estados Unidos) } \\
\text { Monster House (Estados Unidos) }\end{array}$ \\
\hline $\begin{array}{c}80^{\circ} \\
2007\end{array}$ & Ratatouille & Brad Bird & $\begin{array}{l}\text { Estados } \\
\text { Unidos }\end{array}$ & $\begin{array}{c}\text { Persepolis (Francia, Estados } \\
\text { Unidos) } \\
\text { Surf's Up (Estados Unidos) }\end{array}$ \\
\hline $\begin{array}{c}81^{\circ} \\
2008\end{array}$ & WALL-E & Andrew Stanton & $\begin{array}{l}\text { Estados } \\
\text { Unidos }\end{array}$ & $\begin{array}{c}\text { Bolt (Estados Unidos) } \\
\text { Kung Fu Panda (Estados Unidos) }\end{array}$ \\
\hline $\begin{array}{c}82^{\circ} \\
2009\end{array}$ & Up & $\begin{array}{l}\text { Pete Docter, Bob } \\
\text { Peterson }\end{array}$ & $\begin{array}{l}\text { Estados } \\
\text { Unidos }\end{array}$ & $\begin{array}{c}\text { Coraline (Estados Unidos) } \\
\text { Fantastic Mr. Fox (Estados Unidos) } \\
\text { The Princess and the Frog (Estados } \\
\text { Unidos) } \\
\text { The Secret of Kells (Francia, } \\
\text { Irlanda, Bélxica) }\end{array}$ \\
\hline $\begin{array}{c}83^{\circ} \\
2010\end{array}$ & Toy Story 3 & Lee Unkrich & $\begin{array}{l}\text { Estados } \\
\text { Unidos }\end{array}$ & $\begin{array}{c}\text { How to Train Your Dragon (Estados } \\
\text { Unidos) } \\
\text { L'Illusionniste (Francia, Reino } \\
\text { Unido) }\end{array}$ \\
\hline $\begin{array}{c}84^{\circ} \\
2011\end{array}$ & Rango & Gore Verbinski & $\begin{array}{l}\text { Estados } \\
\text { Unidos }\end{array}$ & $\begin{array}{c}\text { Chico \& Rita (España) } \\
\text { Kung Fu Panda } 2 \text { (Estados Unidos) } \\
\text { Puss in Boots (Estados Unidos) } \\
\text { Une vie de chat (Francia, Bélxica) }\end{array}$ \\
\hline $\begin{array}{c}85^{\circ} \\
2012\end{array}$ & Brave & $\begin{array}{l}\text { Mark Andrews, } \\
\text { Brenda } \\
\text { Chapman }\end{array}$ & $\begin{array}{l}\text { Estados } \\
\text { Unidos }\end{array}$ & $\begin{array}{c}\text { Frankenweenie (Estados Unidos) } \\
\text { ParaNorman (Estados Unidos) } \\
\text { The Pirates! In an adventure with } \\
\text { scientists (Reino Unido, Estados } \\
\text { Unidos) } \\
\text { Wreck-lt Ralph (Estados Unidos) }\end{array}$ \\
\hline $\begin{array}{c}86^{\circ} \\
2013\end{array}$ & Frozen & $\begin{array}{l}\text { Chris Buck, } \\
\text { Jennifer Lee }\end{array}$ & $\begin{array}{l}\text { Estados } \\
\text { Unidos }\end{array}$ & $\begin{array}{l}\text { The Croods (Estados Unidos) } \\
\text { Despicable Me } 2 \text { (Estados Unidos) } \\
\text { Ernest et Célestine (Francia, } \\
\text { Bélxica, Luxemburgo) } \\
\text { El viento se levanta (Xapón) }\end{array}$ \\
\hline
\end{tabular}




\begin{tabular}{|c|c|c|c|c|}
\hline $\begin{array}{c}87^{\circ} \\
2014\end{array}$ & Big Hero 6 & $\begin{array}{l}\text { Dean Deblois, } \\
\text { Chris Williams }\end{array}$ & $\begin{array}{l}\text { Estados } \\
\text { Unidos }\end{array}$ & $\begin{array}{c}\text { The Boxtrolls (Estados Unidos) } \\
\text { How to train your dragon } 2 \\
\text { (Estados Unidos) } \\
\text { El cuento de la princesa Kayuga } \\
\text { (Xapón) } \\
\text { Song of the Sea (Irlanda, Bélxica, } \\
\text { Francia, Luxemburgo, Dinamarca) }\end{array}$ \\
\hline $\begin{array}{c}88^{\circ} \\
2015\end{array}$ & Inside Out & $\begin{array}{l}\text { Peter Docter, } \\
\text { Ronnie del } \\
\text { Carmen }\end{array}$ & $\begin{array}{l}\text { Estados } \\
\text { Unidos }\end{array}$ & $\begin{array}{c}\text { Anomalisa (Estados Unidos) } \\
\text { O Menino e o Mundo (Brasil) } \\
\text { Shaun the Sheep Movie (Reino } \\
\text { Unido) } \\
\text { El recuerdo de Marnie (Xapón) }\end{array}$ \\
\hline $\begin{array}{l}89^{\circ} \\
2016\end{array}$ & Zootopia & $\begin{array}{l}\text { Byron Howard, } \\
\text { Rich Moore, } \\
\text { Jared Bush }\end{array}$ & $\begin{array}{l}\text { Estados } \\
\text { Unidos }\end{array}$ & $\begin{array}{c}\text { Kubo and the Two Strings (Estados } \\
\text { Unidos) } \\
\text { Ma vie de Courgette (Suiza, } \\
\text { Francia) } \\
\text { Moana (Estados Unidos) } \\
\text { La tortue rouge (Francia) }\end{array}$ \\
\hline $\begin{array}{c}90^{\circ} \\
2017\end{array}$ & Coco & Lee Unkrich & $\begin{array}{l}\text { Estados } \\
\text { Unidos }\end{array}$ & $\begin{array}{c}\text { The Boss Baby (Estados Unidos) } \\
\text { The Breadwinner (Canadá, Irlanda, } \\
\text { Luxemburgo) } \\
\text { Ferdinand (Estados Unidos) } \\
\text { Loving Vincent (Polonia, Reino } \\
\text { Unido) }\end{array}$ \\
\hline $\begin{array}{c}91^{\circ} \\
2018\end{array}$ & $\begin{array}{c}\text { Spider-Man: } \\
\text { Into the Spider- } \\
\text { Verse }\end{array}$ & $\begin{array}{l}\text { Bob Persichetti, } \\
\text { Peter Ramsey, } \\
\text { Rodney Rothman }\end{array}$ & $\begin{array}{l}\text { Estados } \\
\text { Unidos }\end{array}$ & $\begin{array}{c}\text { Incredibles } 2 \text { (Estados Unidos) } \\
\text { Isle of Dogs (Estados Unidos) } \\
\text { Mirai, mi hermana pequeña } \\
\text { (Xapón) } \\
\text { Ralph Breaks the Internet (Estados } \\
\text { Unidos) }\end{array}$ \\
\hline $\begin{array}{l}92^{\circ} \\
2019\end{array}$ & Toy Story 4 & Josh Cooley & $\begin{array}{l}\text { Estados } \\
\text { Unidos }\end{array}$ & $\begin{array}{l}\text { How to Train Your Dragon: The } \\
\text { Hidden World (Estados Unidos) } \\
\text { J'ai perdu mon corps (Francia) } \\
\text { Klaus (España) } \\
\text { Missing Link (Estados Unidos) }\end{array}$ \\
\hline
\end{tabular}

- Premios Annie: galardóns entregados pola Asociación Internacional de Películas Animadas afincada nos Ánxeles, California, dende 1972. Aínda que se crearon para premiar filmes animados, agora tamén se outorgan a produtos televisivos e videoxogos. No 1992 creouse o premio Annie á mellor película animada e a primeira película gañadora foi Beauty and the Beast (1991). O seguinte cadro recolle os datos dos nomeados e gañadores das distintas edicións:

\begin{tabular}{|c|c|c|c|c|}
\hline Año & Película & Director & País & Nomeadas \\
\hline $20^{\circ}$ & $\begin{array}{c}\text { Beauty and the } \\
\text { Beast }\end{array}$ & $\begin{array}{c}\text { Gary Trousdale, } \\
\text { Kirk Wise }\end{array}$ & $\begin{array}{c}\text { Estados } \\
\text { Unidos }\end{array}$ & $\begin{array}{c}\text { Bébé's Kids (Estados Unidos) } \\
\text { FernGully: The Last Rainforest } \\
\text { (Australia, Estados Unidos) }\end{array}$ \\
\hline
\end{tabular}




\begin{tabular}{|c|c|c|c|c|}
\hline $\begin{array}{c}21^{\circ} \\
1993\end{array}$ & Aladdin & $\begin{array}{l}\text { Ron Clements, } \\
\text { John Musker }\end{array}$ & $\begin{array}{l}\text { Estados } \\
\text { Unidos }\end{array}$ & $\begin{array}{c}\text { Little Nemo (Xapón, Estados Unidos) } \\
\text { Once Upon a Forest (Reino Unido, } \\
\text { Estados Unidos) }\end{array}$ \\
\hline $\begin{array}{c}22^{\circ} \\
1994\end{array}$ & The Lion King & $\begin{array}{l}\text { Roger Allers, } \\
\text { Rob Minkoff }\end{array}$ & $\begin{array}{l}\text { Estados } \\
\text { Unidos }\end{array}$ & $\begin{array}{l}\text { Batman: Mask of the Phantasm } \\
\text { (Estados Unidos) } \\
\text { The Nightmare Before Christmas } \\
\text { (Estados Unidos) }\end{array}$ \\
\hline $\begin{array}{c}23^{\circ} \\
1995\end{array}$ & Pocahontas & $\begin{array}{l}\text { Mike Gabriel, } \\
\text { Eric Goldberg }\end{array}$ & $\begin{array}{l}\text { Estados } \\
\text { Unidos }\end{array}$ & $\begin{array}{l}\text { A Goofy Movie (Estados Unidos) } \\
\text { The Swan Princess (Estados Unidos) }\end{array}$ \\
\hline $\begin{array}{l}24^{\circ} \\
1996\end{array}$ & Toy Story & John Lasseter & $\begin{array}{l}\text { Estados } \\
\text { Unidos }\end{array}$ & $\begin{array}{l}\text { The Hunchback of Notre Dame } \\
\text { (Estados Unidos) } \\
\text { James and the Giant Peach (Estados } \\
\text { Unidos) }\end{array}$ \\
\hline $\begin{array}{l}25^{\circ} \\
1997\end{array}$ & $\begin{array}{l}\text { Cats Don't } \\
\text { Dance }\end{array}$ & Mark Dindal & $\begin{array}{l}\text { Estados } \\
\text { Unidos }\end{array}$ & $\begin{array}{l}\text { Hercules (Estados Unidos) } \\
\text { Space Jam (Estados Unidos) }\end{array}$ \\
\hline $\begin{array}{c}26^{\circ} \\
1998\end{array}$ & Mulan & $\begin{array}{l}\text { Barry Cook, } \\
\text { Tony Bancroft }\end{array}$ & $\begin{array}{l}\text { Estados } \\
\text { Unidos }\end{array}$ & $\begin{array}{l}\text { Anastasia (Estados Unidos) } \\
\text { I Married a Strange Person (Estados } \\
\quad \text { Unidos) } \\
\text { Quest for Camelot (Estados Unidos) }\end{array}$ \\
\hline $\begin{array}{c}27^{\circ} \\
1999\end{array}$ & The Iron Giant & Brad Bird & $\begin{array}{l}\text { Estados } \\
\text { Unidos }\end{array}$ & $\begin{array}{c}\text { A Bug's Life (Estados Unidos) } \\
\text { The Prince of Egypt (Estados Unidos) } \\
\text { South Park: Bigger, Longer \& Uncut } \\
\text { (Estados Unidos) } \\
\text { Tarzan (Estados Unidos) }\end{array}$ \\
\hline $\begin{array}{c}28^{\circ} \\
2000\end{array}$ & Toy Story 2 & John Lasseter & $\begin{array}{l}\text { Estados } \\
\text { Unidos }\end{array}$ & $\begin{array}{c}\text { Chicken Run (Estados Unidos, Reino } \\
\text { Unido) } \\
\text { Fantasia } 2000 \text { (Estados Unidos) } \\
\text { The Road to El Dorado (Estados } \\
\text { Unidos) } \\
\text { Titan A.E. (Estados Unidos) }\end{array}$ \\
\hline $\begin{array}{c}29^{\circ} \\
2001\end{array}$ & Shrek & $\begin{array}{c}\text { Andrew } \\
\text { Adamson, Vicky } \\
\text { Jenson }\end{array}$ & $\begin{array}{l}\text { Estados } \\
\text { Unidos }\end{array}$ & $\begin{array}{l}\text { Blood: The Last Vampire (Xapón) } \\
\text { The Emperor's New Groove } \\
\text { (Estados Unidos) } \\
\text { Osmosis Jones (Estados Unidos) }\end{array}$ \\
\hline $\begin{array}{c}30^{\circ} \\
2002\end{array}$ & $\begin{array}{l}\text { El viaje de } \\
\text { Chihiro }\end{array}$ & Hayao Miyazaki & Xapón & $\begin{array}{c}\text { Ice Age (Estados Unidos) } \\
\text { Lilo \& Stitch (Estados Unidos) } \\
\text { Monsters, Inc. (Estados Unidos) } \\
\text { Spirit: Stallion of the Cimarron } \\
\text { (Estados Unidos) }\end{array}$ \\
\hline $\begin{array}{c}31^{\circ} \\
2003\end{array}$ & Finding Nemo & Andrew Stanton & $\begin{array}{l}\text { Estados } \\
\text { Unidos }\end{array}$ & $\begin{array}{l}\text { Brother Bear (Estados Unidos) } \\
\text { Looney Tunes: Back In Action } \\
\text { (Estados Unidos) } \\
\text { Millennium Actress (Xapón) } \\
\text { Les Triplettes de Belleville (Francia, } \\
\text { Bélxica, Canadá, Reino Unido) }\end{array}$ \\
\hline $\begin{array}{c}32^{\circ} \\
2004\end{array}$ & The Incredibles & Brad Bird & $\begin{array}{l}\text { Estados } \\
\text { Unidos }\end{array}$ & $\begin{array}{c}\text { Ghost in the Shell 2: Innocence } \\
\text { (Xapón) } \\
\text { Shrek } 2 \text { (Estados Unidos) } \\
\text { The SpongeBob SquarePants Movie } \\
\text { (Estados Unidos) }\end{array}$ \\
\hline
\end{tabular}




\begin{tabular}{|c|c|c|c|c|}
\hline $\begin{array}{c}33^{\circ} \\
2005\end{array}$ & $\begin{array}{l}\text { Wallace \& } \\
\text { Gromit: The } \\
\text { Curse of the } \\
\text { Were-Rabbit }\end{array}$ & $\begin{array}{c}\text { Nick Park, Steve } \\
\text { Box }\end{array}$ & $\begin{array}{l}\text { Estados } \\
\text { Unidos, } \\
\text { Reino Unido }\end{array}$ & $\begin{array}{c}\text { Chicken Little (Estados Unidos) } \\
\text { Corpse Bride (Reino Unido, Estados } \\
\text { Unidos) } \\
\text { El castillo ambulante de Howl } \\
\text { (Xapón) } \\
\text { Madagascar (Estados Unidos) }\end{array}$ \\
\hline $\begin{array}{l}34^{\circ} \\
2006\end{array}$ & Cars & John Lasseter & $\begin{array}{l}\text { Estados } \\
\text { Unidos }\end{array}$ & $\begin{array}{l}\text { Happy Feet (Estados Unidos, } \\
\text { Australia) } \\
\text { Monster House (Estados Unidos) } \\
\text { Open Season (Estados Unidos) } \\
\text { Over the Hedge (Estados Unidos) }\end{array}$ \\
\hline $\begin{array}{c}35^{\circ} \\
2007\end{array}$ & Ratatoville & Brad Bird & $\begin{array}{l}\text { Estados } \\
\text { Unidos }\end{array}$ & $\begin{array}{c}\text { Bee Movie (Estados Unidos) } \\
\text { Persepolis (Francia, Estados Unidos) } \\
\text { The Simpsons Movie (Estados } \\
\text { Unidos) } \\
\text { Surf's Up (Estados Unidos) }\end{array}$ \\
\hline $\begin{array}{l}36^{\circ} \\
2008\end{array}$ & Kung Fu Panda & $\begin{array}{l}\text { John Stevenson, } \\
\text { Mark Osborne }\end{array}$ & $\begin{array}{l}\text { Estados } \\
\text { Unidos }\end{array}$ & $\begin{array}{c}\$ 9.99 \text { (Australia) } \\
\text { Bolt (Estados Unidos) } \\
\text { WALL-E (Estados Unidos) } \\
\text { Waltz with Bashir (Israel, Alemania, } \\
\text { Francia) }\end{array}$ \\
\hline $\begin{array}{c}37^{\circ} \\
2009\end{array}$ & Up & Pete Docter & $\begin{array}{l}\text { Estados } \\
\text { Unidos }\end{array}$ & $\begin{array}{l}\text { Cloudy with a Chance of Meatballs } \\
\text { (Estados Unidos) } \\
\text { Coraline (Estados Unidos) } \\
\text { Fantastic Mr. Fox (Estados Unidos) } \\
\text { The Princess and the Frog (Estados } \\
\text { Unidos) } \\
\text { The Secret of Kells (Francia, Bélxica, } \\
\text { Irlanda) }\end{array}$ \\
\hline $\begin{array}{l}38^{\circ} \\
2010\end{array}$ & $\begin{array}{l}\text { How to Train } \\
\text { Your Dragon }\end{array}$ & $\begin{array}{l}\text { Chris Sanders, } \\
\text { Dean DeBlois }\end{array}$ & $\begin{array}{l}\text { Estados } \\
\text { Unidos }\end{array}$ & $\begin{array}{c}\text { Despicable Me (Estados Unidos) } \\
\text { L'Illusionniste (Francia, Reino Unido) } \\
\text { Tangled (Estados Unidos) } \\
\text { Toy Story } 3 \text { (Estados Unidos) }\end{array}$ \\
\hline $\begin{array}{c}39^{\circ} \\
2011\end{array}$ & Rango & Gore Verbinski & $\begin{array}{l}\text { Estados } \\
\text { Unidos }\end{array}$ & $\begin{array}{l}\text { The Adventures of Tintin: The Secret } \\
\text { of The Unicorn (Estados Unidos, } \\
\text { Nueva Zelanda) } \\
\text { Arthur Christmas (Reino Unido, } \\
\text { Estados Unidos) } \\
\text { Cars } 2 \text { (Estados Unidos) } \\
\text { Chico \& Rita (España) } \\
\text { Une vie de chat (Francia, Bélxica) } \\
\text { Kung Fu Panda } 2 \text { (Estados Unidos) } \\
\text { Puss in Boots (Estados Unidos) } \\
\text { Rio (Estados Unidos) } \\
\text { Arrugas (España) }\end{array}$ \\
\hline $\begin{array}{c}40^{\circ} \\
2012\end{array}$ & Wreck-It Ralph & Rich Moore & $\begin{array}{l}\text { Estados } \\
\text { Unidos }\end{array}$ & $\begin{array}{c}\text { Brave (Estados Unidos) } \\
\text { Frankenweenie (Estados Unidos) } \\
\text { Hotel Transylvania (Estados Unidos) } \\
\text { ParaNorman (Estados Unidos) } \\
\text { The Pirates! In an adventure with } \\
\text { scientists (Reino Unido, Estados } \\
\text { Unidos) } \\
\text { Rise of Guardians (Estados Unidos) } \\
\text { Le Chat du Rabbin (Francia) }\end{array}$ \\
\hline
\end{tabular}




\begin{tabular}{|c|c|c|c|c|}
\hline $\begin{array}{c}41^{\circ} \\
2013\end{array}$ & Frozen & $\begin{array}{l}\text { Chris Buck, } \\
\text { Jennifer Lee }\end{array}$ & $\begin{array}{l}\text { Estados } \\
\text { Unidos }\end{array}$ & $\begin{array}{c}\text { The Croods (Estados Unidos) } \\
\text { Despicable Me } 2 \text { (Estados Unidos) } \\
\text { Ernest et Célestine (Francia, Bélxica, } \\
\text { Luxemburgo) } \\
\text { A Letter to Momo (Xapón) } \\
\text { Monsters University (Estados } \\
\text { Unidos) } \\
\text { El viento se levanta (Xapón) }\end{array}$ \\
\hline $\begin{array}{c}42^{\circ} \\
2014\end{array}$ & $\begin{array}{l}\text { How to Train } \\
\text { Your Dragon } 2\end{array}$ & Dean DeBlois & $\begin{array}{l}\text { Estados } \\
\text { Unidos }\end{array}$ & $\begin{array}{c}\text { Big Hero } 6 \text { (Estados Unidos) } \\
\text { The Book of Life (Estados Unidos) } \\
\text { The Boxtrolls (Estados Unidos) } \\
\text { Cheatin' (Estados Unidos) } \\
\text { The Lego Movie (Estados Unidos) } \\
\text { Song of the Sea (Irlanda, Bélxica, } \\
\text { Francia, Luxemburgo, Dinamarca) } \\
\text { El cuento de la princesa Kaguya } \\
\text { (Xapón) }\end{array}$ \\
\hline $\begin{array}{c}43^{\circ} \\
2015\end{array}$ & Inside Out & $\begin{array}{l}\text { Peter Docter, } \\
\text { Ronnie del } \\
\text { Carmen }\end{array}$ & $\begin{array}{l}\text { Estados } \\
\text { Unidos }\end{array}$ & $\begin{array}{l}\text { Anomalisa (Estados Unidos) } \\
\text { The Good Dinosaur (Estados } \\
\text { Unidos) } \\
\text { The Peanuts Movie (Estados Unidos) } \\
\text { Shaun the Sheep Movie (Reino } \\
\text { Unido) }\end{array}$ \\
\hline $\begin{array}{c}44^{\circ} \\
2016\end{array}$ & Zootopia & $\begin{array}{l}\text { Byron Howard, } \\
\text { Rich Moore }\end{array}$ & $\begin{array}{l}\text { Estados } \\
\text { Unidos }\end{array}$ & $\begin{array}{c}\text { Finding Dory (Estados Unidos) } \\
\text { Kubo and the Two Strings (Estados } \\
\text { Unidos) } \\
\text { Kung Fu Panda } 3 \text { (Estados Unidos) } \\
\text { Moana (Estados Unidos) }\end{array}$ \\
\hline $\begin{array}{c}45^{\circ} \\
2017\end{array}$ & Coco & Lee Unkrich & $\begin{array}{l}\text { Estados } \\
\text { Unidos }\end{array}$ & $\begin{array}{l}\text { The Boss Baby (Estados Unidos) } \\
\text { Captain Underpants: The First Epic } \\
\text { Movie (Estados Unidos) } \\
\text { Cars } 3 \text { (Estados Unidos) } \\
\text { Despicable Me } 3 \text { (Estados Unidos) }\end{array}$ \\
\hline $\begin{array}{c}46^{\circ} \\
2018\end{array}$ & $\begin{array}{c}\text { Spider-Man: } \\
\text { Into de Spider- } \\
\text { Verse }\end{array}$ & $\begin{array}{l}\text { Bob Persichetti, } \\
\text { Peter Ramsey, } \\
\text { Rodney Rothman }\end{array}$ & $\begin{array}{l}\text { Estados } \\
\text { Unidos }\end{array}$ & $\begin{array}{c}\text { Early Man (Reino Unido) } \\
\text { Incredibles } 2 \text { (Estados Unidos) } \\
\text { Isle of Dogs (Estados Unidos) } \\
\text { Ralph Breaks the Internet (Estados } \\
\text { Unidos) }\end{array}$ \\
\hline $\begin{array}{c}47^{\circ} \\
2019\end{array}$ & Klaus & Sergio Pablos & España & $\begin{array}{l}\text { Frozen } 2 \text { (Estados Unidos) } \\
\text { How to Train Your Dragon: The } \\
\text { Hidden World (Estados Unidos) } \\
\text { Missing Link (Estados Unidos) } \\
\text { Toy Story } 4 \text { (Estados Unidos) }\end{array}$ \\
\hline
\end{tabular}

- Globos de Ouro: galardóns concedidos polos membros da Asociación da Prensa Estranxeira de Hollywood en recoñecemento ao labor dos profesionais do cine e da televisión a nivel mundial. A primeira cerimonia celebrouse no 1944 e, a partir da 64 edición, conta cunha categoría dedicada á mellor película animada, cuxa primeira gañadora foi Cars (2006). A continuación inclúese o cadro cos distintos nomeados e gañadores: 


\begin{tabular}{|c|c|c|c|c|}
\hline $\begin{array}{l}\text { Edición/ } \\
\text { Ano }\end{array}$ & Película & Director & País & Nomeadas \\
\hline $\begin{array}{c}64^{\circ} \\
2006\end{array}$ & Cars & John Lasseter & $\begin{array}{l}\text { Estados } \\
\text { Unidos }\end{array}$ & $\begin{array}{l}\text { Happy Feet (Estados Unidos) } \\
\text { Monster House (Estados Unidos) }\end{array}$ \\
\hline $\begin{array}{c}65^{\circ} \\
2007\end{array}$ & Ratatouille & Brad Bird & $\begin{array}{l}\text { Estados } \\
\text { Unidos }\end{array}$ & $\begin{array}{c}\text { Bee Movie (Estados Unidos) } \\
\text { The Simpsons Movie (Estados } \\
\text { Unidos) }\end{array}$ \\
\hline $\begin{array}{l}66^{\circ} \\
2008\end{array}$ & WALL-E & Andrew Stanton & $\begin{array}{l}\text { Estados } \\
\text { Unidos }\end{array}$ & $\begin{array}{c}\text { Bolt (Estados Unidos) } \\
\text { Kung Fu Panda (Estados Unidos) }\end{array}$ \\
\hline $\begin{array}{c}67^{\circ} \\
2009\end{array}$ & Up & Pete Docter & $\begin{array}{l}\text { Estados } \\
\text { unidos }\end{array}$ & $\begin{array}{c}\text { Cloudy with a Chance of Meatballs } \\
\text { (Estados Unidos) } \\
\text { Coraline (Estados Unidos) } \\
\text { Fantastic Mr. Fox (Estados Unidos) } \\
\text { The Princess and the Frog (Estados } \\
\text { Unidos) }\end{array}$ \\
\hline $\begin{array}{c}68^{\circ} \\
2010\end{array}$ & Toy Story 3 & Lee Unkrich & $\begin{array}{l}\text { Estados } \\
\text { Unidos }\end{array}$ & $\begin{array}{c}\text { Despicable Me (Estados Unidos) } \\
\text { How to Train Your Dragon (Estados } \\
\text { Unidos) } \\
\text { L'Illusionniste (Francia, Reino Unido) } \\
\text { Tangled (Estados Unidos) }\end{array}$ \\
\hline $\begin{array}{c}69^{\circ} \\
2011\end{array}$ & $\begin{array}{l}\text { The Adventures } \\
\text { of Tintin: The } \\
\text { Secret of The } \\
\text { Unicorn }\end{array}$ & Steven Spielberg & $\begin{array}{l}\text { Estados } \\
\text { Unidos, } \\
\text { Nueva } \\
\text { Zelanda }\end{array}$ & $\begin{array}{l}\text { Arthur Christmas (Estados Unidos) } \\
\text { Cars } 2 \text { (Estados Unidos) } \\
\text { Puss in Boots (Estados Unidos) } \\
\text { Rango (Estados Unidos) }\end{array}$ \\
\hline $\begin{array}{l}70^{\circ} \\
2012\end{array}$ & Brave & $\begin{array}{l}\text { Mark Andrews, } \\
\text { Brenda } \\
\text { Chapman }\end{array}$ & $\begin{array}{l}\text { Estados } \\
\text { Unidos }\end{array}$ & $\begin{array}{c}\text { Frankenweenie (Estados Unidos) } \\
\text { Hotel Transylvania (Estados Unidos) } \\
\text { Rise of the Guardians (Estados } \\
\text { Unidos) } \\
\text { Wreck-It Ralph (Estados Unidos) }\end{array}$ \\
\hline $\begin{array}{c}71^{\circ} \\
2013 \\
\end{array}$ & Frozen & $\begin{array}{l}\text { Chris Buck, } \\
\text { Jennifer Lee }\end{array}$ & $\begin{array}{l}\text { Estados } \\
\text { Unidos }\end{array}$ & $\begin{array}{l}\text { The Croods (Estados Unidos) } \\
\text { Despicable Me } 2 \text { (Estados Unidos) }\end{array}$ \\
\hline $\begin{array}{l}72^{\circ} \\
2014\end{array}$ & $\begin{array}{l}\text { How to Train } \\
\text { Your Dragon } 2\end{array}$ & Dean DeBlois & $\begin{array}{l}\text { Estados } \\
\text { Unidos }\end{array}$ & $\begin{array}{l}\text { Big Hero } 6 \text { (Estados Unidos) } \\
\text { The Book of Life (Estados Unidos) } \\
\text { The Boxtrolls (Estados Unidos) } \\
\text { The Lego Movie (Estados Unidos) }\end{array}$ \\
\hline $\begin{array}{l}73^{\circ} \\
2015\end{array}$ & Inside Out & $\begin{array}{l}\text { Peter Docter, } \\
\text { Ronnie del } \\
\text { Carmen }\end{array}$ & $\begin{array}{l}\text { Estados } \\
\text { Unidos }\end{array}$ & $\begin{array}{l}\text { Anomalisa (Estados Unidos) } \\
\text { The Good Dinosaur (Estados } \\
\text { Unidos) } \\
\text { The Peanuts Movie (Estados Unidos) } \\
\text { Shaun the Sheep Movie (Reino } \\
\text { Unido) }\end{array}$ \\
\hline $\begin{array}{l}74^{\circ} \\
2016\end{array}$ & Zootopia & $\begin{array}{l}\text { Byron Howard, } \\
\text { Rich Moore }\end{array}$ & $\begin{array}{l}\text { Estados } \\
\text { Unidos }\end{array}$ & $\begin{array}{c}\text { Kubo and the Two Strings (Estados } \\
\text { Unidos) } \\
\text { Moana (Estados Unidos) } \\
\text { Sing (Estados Unidos) } \\
\text { Ma vie de Courgette (Suiza, } \\
\text { Francia) }\end{array}$ \\
\hline $\begin{array}{l}75^{\circ} \\
2017\end{array}$ & Coco & Lee Unkrich & $\begin{array}{l}\text { Estados } \\
\text { Unidos }\end{array}$ & $\begin{array}{c}\text { The Boss Baby (Estados Unidos) } \\
\text { The Breadwinner (Canadá, Irlanda, } \\
\text { Luxemburgo) } \\
\text { Ferdinand (Estados Unidos) } \\
\text { Loving Vincent (Polonia, Reino } \\
\text { Unido) }\end{array}$ \\
\hline
\end{tabular}




\begin{tabular}{|c|c|c|c|c|}
\hline $76^{\circ}$ & $\begin{array}{c}\text { Spider-Man: } \\
\text { Into the Spider- } \\
\text { Verse }\end{array}$ & $\begin{array}{c}\text { Bob Persichetti, } \\
\text { Peter Ramsey, } \\
\text { Rodney Rothman }\end{array}$ & $\begin{array}{c}\text { Estados } \\
\text { Unidos }\end{array}$ & $\begin{array}{c}\text { Incredibles 2 (Estados Unidos) } \\
\text { Isle of Dogs (Estados Unidos) } \\
\text { Mirai, mi hermana pequeña } \\
\text { (Xapón) }\end{array}$ \\
$77^{\circ}$ & Missing Link & Chris Butler & $\begin{array}{c}\text { Ralph Breaks the Internet (Estados } \\
\text { Unidos) }\end{array}$ \\
\hline 2019 & $\begin{array}{c}\text { Estados } \\
\text { Unidos }\end{array}$ & $\begin{array}{c}\text { Frozen 2 (Estados Unidos) } \\
\text { How to Train Your Dragon: The } \\
\text { Hidden World (Estados Unidos) } \\
\text { The Lion King (Estados Unidos) } \\
\text { Toy Story 4 (Estados Unidos) }\end{array}$ \\
\hline
\end{tabular}

- Premios BAFTA: galardóns outorgados pola Academia Británica das Artes Cinematográficas e da Televisión cuxa primeira entrega tivo lugar no $1947 . \mathrm{Na} 60^{\mathrm{a}}$ edición creouse a categoría de longametraxes animadas e a primeira película gañadora foi Happy Feet (2006). Os distintos nomeados e premiados foron os seguintes:

\begin{tabular}{|c|c|c|c|c|}
\hline $\begin{array}{l}\text { Edición/ } \\
\text { Ano }\end{array}$ & Película & Director & País & Nomeadas \\
\hline $\begin{array}{c}60^{\circ} \\
2007\end{array}$ & Happy Feet & $\begin{array}{l}\text { Geroge Miller, } \\
\text { Warren } \\
\text { Coleman, Judy } \\
\text { Morris }\end{array}$ & $\begin{array}{l}\text { Estados } \\
\text { Unidos, } \\
\text { Australia }\end{array}$ & $\begin{array}{l}\text { Cars (Estados Unidos) } \\
\text { Flushed Away (Reino Unido, } \\
\text { Estados Unidos) }\end{array}$ \\
\hline $\begin{array}{c}61^{\circ} \\
2008\end{array}$ & Ratatoville & $\begin{array}{l}\text { Brad Bird, Jan } \\
\text { Pinkava }\end{array}$ & $\begin{array}{l}\text { Estados } \\
\text { Unidos }\end{array}$ & $\begin{array}{c}\text { Shrek the Third (Estados Unidos) } \\
\text { The Simpsons Movie (Estados } \\
\text { Unidos) }\end{array}$ \\
\hline $\begin{array}{c}62^{\circ} \\
2009\end{array}$ & WALL-E & Andrew Stanton & $\begin{array}{l}\text { Estados } \\
\text { Unidos }\end{array}$ & $\begin{array}{c}\text { Persepolis (Francia, Estados } \\
\text { Unidos) } \\
\text { Waltz with Bashir (Israel, } \\
\text { Alemania, Francia) }\end{array}$ \\
\hline $\begin{array}{c}63^{\circ} \\
2010\end{array}$ & Up & $\begin{array}{l}\text { Pete Docter, Bob } \\
\text { Peterson }\end{array}$ & $\begin{array}{l}\text { Estados } \\
\text { Unidos }\end{array}$ & $\begin{array}{c}\text { Coraline (Estados Unidos) } \\
\text { Fantastic Mr. Fox (Estados Unidos) }\end{array}$ \\
\hline $\begin{array}{c}64^{\circ} \\
2011\end{array}$ & Toy Story 3 & Lee Unkrich & $\begin{array}{l}\text { Estados } \\
\text { Unidos }\end{array}$ & $\begin{array}{c}\text { Despicable Me (Estados Unidos) } \\
\text { How to Train Your Dragon (Estados } \\
\text { Unidos) }\end{array}$ \\
\hline $\begin{array}{c}65^{\circ} \\
2012\end{array}$ & Rango & Gore Verbinski & $\begin{array}{l}\text { Estados } \\
\text { Unidos }\end{array}$ & $\begin{array}{l}\text { The Adventures of Tintin: The Secret } \\
\text { of The Unicorn (Estados Unidos, } \\
\text { Nueva Zelanda) } \\
\text { Arthur Christmas (Reino Unido, } \\
\text { Estados Unidos) }\end{array}$ \\
\hline $\begin{array}{c}66^{\circ} \\
2013\end{array}$ & Brave & $\begin{array}{l}\text { Mark Andrews, } \\
\text { Brenda } \\
\text { Chapman }\end{array}$ & $\begin{array}{l}\text { Estados } \\
\text { Unidos }\end{array}$ & $\begin{array}{l}\text { Frankenweenie (Estados Unidos) } \\
\text { ParaNorman (Estados Unidos) }\end{array}$ \\
\hline $\begin{array}{c}67^{\circ} \\
2014\end{array}$ & Frozen & $\begin{array}{l}\text { Chris Buck, } \\
\text { Jennifer Lee }\end{array}$ & $\begin{array}{l}\text { Estados } \\
\text { Unidos }\end{array}$ & $\begin{array}{c}\text { Despicable Me } 2 \text { (Estados Unidos) } \\
\text { Monsters University (Estados } \\
\text { Unidos) }\end{array}$ \\
\hline
\end{tabular}




\begin{tabular}{|c|c|c|c|c|}
\hline $\begin{array}{c}68^{\circ} \\
2015\end{array}$ & The Lego Movie & $\begin{array}{l}\text { Phil Lord, } \\
\text { Christopher } \\
\text { Miller }\end{array}$ & $\begin{array}{l}\text { Estados } \\
\text { Unidos, } \\
\text { Dinamarca, } \\
\text { Australia }\end{array}$ & $\begin{array}{l}\text { Big Hero } 6 \text { (Estados Unidos) } \\
\text { The Boxtrolls (Estados Unidos) }\end{array}$ \\
\hline $\begin{array}{l}69^{\circ} \\
2016\end{array}$ & Inside Out & $\begin{array}{l}\text { Peter Docter, } \\
\text { Ronnie del } \\
\text { Carmen }\end{array}$ & $\begin{array}{l}\text { Estados } \\
\text { Unidos }\end{array}$ & $\begin{array}{c}\text { Minions (Estados Unidos) } \\
\text { Shaun the Sheep Movie (Reino } \\
\text { Unido) }\end{array}$ \\
\hline $\begin{array}{l}70^{\circ} \\
2017\end{array}$ & $\begin{array}{l}\text { Kubo and the } \\
\text { Two Strings }\end{array}$ & Travis Knight & $\begin{array}{l}\text { Estados } \\
\text { Unidos }\end{array}$ & $\begin{array}{c}\text { Finding Dory (Estados Unidos) } \\
\text { Moana (Estados Unidos) } \\
\text { Zootopia (Estados Unidos) }\end{array}$ \\
\hline $\begin{array}{l}71^{\circ} \\
2018\end{array}$ & Coco & Lee Unkrich & $\begin{array}{l}\text { Estados } \\
\text { Unidos }\end{array}$ & $\begin{array}{l}\text { Loving Vincent (Polonia, Reino } \\
\text { Unido) } \\
\text { Ma vie de Courgette (Suiza, } \\
\text { Francia) }\end{array}$ \\
\hline $\begin{array}{l}72^{\circ} \\
2019\end{array}$ & $\begin{array}{l}\text { Spider-Man: } \\
\text { Into the Spider- } \\
\text { verse }\end{array}$ & $\begin{array}{l}\text { Bob Persichetti, } \\
\text { Peter Ramsey, } \\
\text { Rodney Rothman }\end{array}$ & $\begin{array}{l}\text { Estados } \\
\text { Unidos }\end{array}$ & $\begin{array}{c}\text { Incredibles } 2 \text { (Estados Unidos) } \\
\text { Isle of Dogs (Estados Unidos) }\end{array}$ \\
\hline $\begin{array}{l}73^{\circ} \\
2020\end{array}$ & Klaus & Sergio Pablos & España & $\begin{array}{l}\text { Frozen } 2 \text { (Estados Unidos) } \\
\text { A Shaun the Sheep Movie: } \\
\text { Farmageddon (Reino Unido) } \\
\text { Toy Story } 4 \text { (Estados Unidos) }\end{array}$ \\
\hline
\end{tabular}

No destaque de reescrituras decidiuse deixar fóra aquelas películas que parten de personaxes literarios coñecidos, pero cuxa versión fílmica se afasta tanto deles por distintos motivos, especialmente humorísticos ou a súa adecuación aos intereses da infancia, que se fai difícil pensar nelas como hipertextos fílmicos. Este sería o caso da película Frankenweenie ou de Hotel Transylvania, que collen a idea das personaxes do monstro de Frankenstein e do Conde Drácula respectivamente. Outra característica recorrente do fenómeno é a diminución progresiva do grao de dependencia constitutiva ${ }^{4}$ a propósito da sucesión de secuelas fílmicas. Este sería o caso da adaptación libre do conto protagonizado pola Raíña das Neves de Hans Christian Andersen que corresponde á película Frozen (2013) que, en Frozen 2 (2019), continúa con un guión totalmente orixinal; ou no caso das aventuras do ogro Shrek, que a partir dun conto infantil escrito e ilustrado por William Steig dá lugar a un universo cinematográfico novo, independente e con moito éxito que se compón de catro películas, Shrek (2001), Shrek 2 (2004), Shrek the Third (2007), e Shrek Forever After (2010). Ademais, a inclusión de personaxes como o Gato con Botas,

4 O grao de dependencia constitutiva da reescritura fílmica con respecto ao hipotexto literario é un dos criterios fundamentais que utiliza José Luis Sánchez Noriega (2000) para ofrecer unha clasificación do tipo de reescritura que vai de máis a menos referencialidade, e inclúe a adaptación como ilustración, transposición, interpretación ou adaptación libre. 
protagonista dun conto popular recollido por Charles Perrault, dou lugar a unha obra derivada que bebe tanto do hipotexto literario como destas películas, Puss in Boots (2011), que tamén foi nomeada aos Óscar na edición 84a .

Do mesmo xeito que sucedeu coa historia do ogro Shrek, as reescrituras de álbums ilustrados tenden a levar a cabo un exercicio de ampliación do material de partida co obxectivo de adaptar unha obra relativamente curta na súa trama á duración das longametraxes. Sería o caso de Cloudy with a Chance of Meatballs (2009), escrita por Judi Barrett e ilustrado por Ron Barrett; Ernest et Célestine (2012), baseada na serie de libros infantís homónima da autoría de Gabrielle Vincent, cuxa estética é mantida na versión fílmica; The Boss Baby (2017), a partir do álbum de Marla Frazee; ou Ferdinand (2017), a partir do álbum de Munro Leaf e Robert Lawson.

No caso das reescrituras de novelas ou sagas, estamos ante un grupo bastante amplo no cal podemos diferenciar as reescrituras de series literarias como a protagonizada por Hipo o vikingo, escrita por Cressida Cowell para público infantil, cuxos hipertextos fílmicos son a triloxía composta por How to Train your Dragon (2010), How to Train Your Dragon 2 (2014) e How to Train 36 your Dragon: The Hidden World (2019); a película The Pirates! In an adventure with Scientists (2012), que reescribe a primeira entrega da serie de novelas protagonizadas por piratas de Gideon Defoe; Rise of Guardians (2012), que se basea na serie dos Gardiáns da Infancia de William Joyce, composta por novelas e álbums; ou Captain Underpants: The First Epic Movie (2017), cuxo protagonista foi concibido por Dav Pilkey para unha serie de libros de aventuras moi vendidos até o día de hoxe.

Se falamos de libros autoconclusivos, podemos atoparnos reescrituras de novelas infantís como The Iron Giant (1999), cuxo hipotexto foi realizado por Ted Hughes; Fantastic Mr. Fox (2009), a partir dunha novela da autoría de Roald Dahl ou The Boxtrolls (2004), a partir dunha obra de Alan Snow; e outras obras máis xuvenís, como El castillo ambulante de Howl (2004), adaptación dunha novela de Diana Wynne Jones; Coraline (2009), que reescribe unha novela de Neil Gaiman; El recuerdo de Marnie (2014), adaptación dunha novela de Joan G. Robinson; Ma vie de Courgette (2016), a partir dunha novela de Gilles Paris; ou The Breadwinner (2017), que reescribe a novela de Deborah Ellis. Tamén están presentes as reescrituras de novelas de adultos máis próximas ao hipotexto literario, como f'ai perdu mon corps (2019), baseada nunha novela de Guillaume Laurant, e outras que cambian totalmente pensando 
nos máis novos, como Treasure Island (2002), que bebe da novela de Robert Louis Stevenson, pero sitúa a trama no espacio exterior, ou Tarzan (1999), baseada na serie de novelas de Edgar Rice Burroughs.

Por último, outra fenómeno recorrente é a reescritura de novelas gráficas, como Persepolis (2007) ou Arrugas (2011), que manteñen o estilo visual na translación á gran pantalla, series de cómics xuvenís de fama mundial como The Adventures of Tintin: The Secret of The Unicorn (2011), e personaxes recoñecidos de tiras cómicas como The Peanuts Movie (2015). Ademais, tamén tiveron moi boa acollida a reescritura de historias de superheroes, especialmente do universo Marvel, con personaxes xuvenís como Big Hero 6 (2014), ou a versión do home araña que protagoniza Miles Morales, un adolescente de pai afroamericano e nai portorriqueña, na película Spider-Man: Into the Spider-verse (2018).

Facendo balance de todos os nomeados e premiados relacionados ao longo dos anos, no caso dos Óscar foron propostas oitenta películas, das cales vinte e dúas parten de narrativas, e catro de bandas deseñadas (en total vinte e seis, o cal supón o 32,5\% do total); no caso dos Annie, do total de centro trinta e nove películas, vinte e oito son narrativas e doce bandas deseñadas (sumando corenta, o 28,8\%); nos Globos de Ouro, das sesenta e dúas películas nomeadas, dezasete foron baseadas en narrativas e catro en cómics (en total vinte e unha, o 33,9\% do total); e, por último, no caso dos BAFTA, das corenta e catro películas, oito parten de narrativas e catro de bandas deseñadas (en total doce, o $27,3 \%$ dos filmes).

Se nos centramos agora no que son as premiados, as reescrituras fílmicas que conseguiron os catro galardóns foron Frozen e Spider-Man: Into the Spider-verse, seguidas de Shrek e How to Train your Dragon 2 con dous. Non obstante, cómpre destacar que os Globos de Ouro e os BAFTA comezaron a convocarse despois de ter saído a película baseada na novela de Steig, polo que conseguiu os premios nos que tivo a posibilidade de estar nomeada. As catro películas mencionadas foron realizades con animación dixital 3D. A produtora de Frozen foi Walt Disney Pictures, a do superheroe arácnido Sony Pictures Animation en asociación con Marvel Entertainment, e as dúas restantes pertencen a Dreamworks Animation.

Entre as demais non gañadoras podemos atopar outras técnicas de animación como o claymotion ou stopmotion con plastilina de The Pirates! In an 
adventure with scientists, de Aardman Studios, especialistas neste tipo de producións. Outro estudio de animación especializado no stopmotion, pero desta volta con marionetas, é Laika, responsable de varias películas nomeadas como The Boxtrolls ou Coraline, ademais doutras que contan con guión orixinal, entre as que destaca a recente Missing Link, gañadora dun Globo de Ouro.

Por último, compre recordar unha das vantaxes xa adiantada que tende a traer a realización dunha reescritura fílmica para a obra literaria, a reedición dos hipotextos no ano de estrea das películas, cuxas cubertas solen cambiar por unha escena ou fotograma da película e, a miúdo, inclúen un paratexto verbal que chama a atención sobre a existencia do filme. Algúns exemplos serían os das obras ás que lles corresponden as seguintes cubertas:
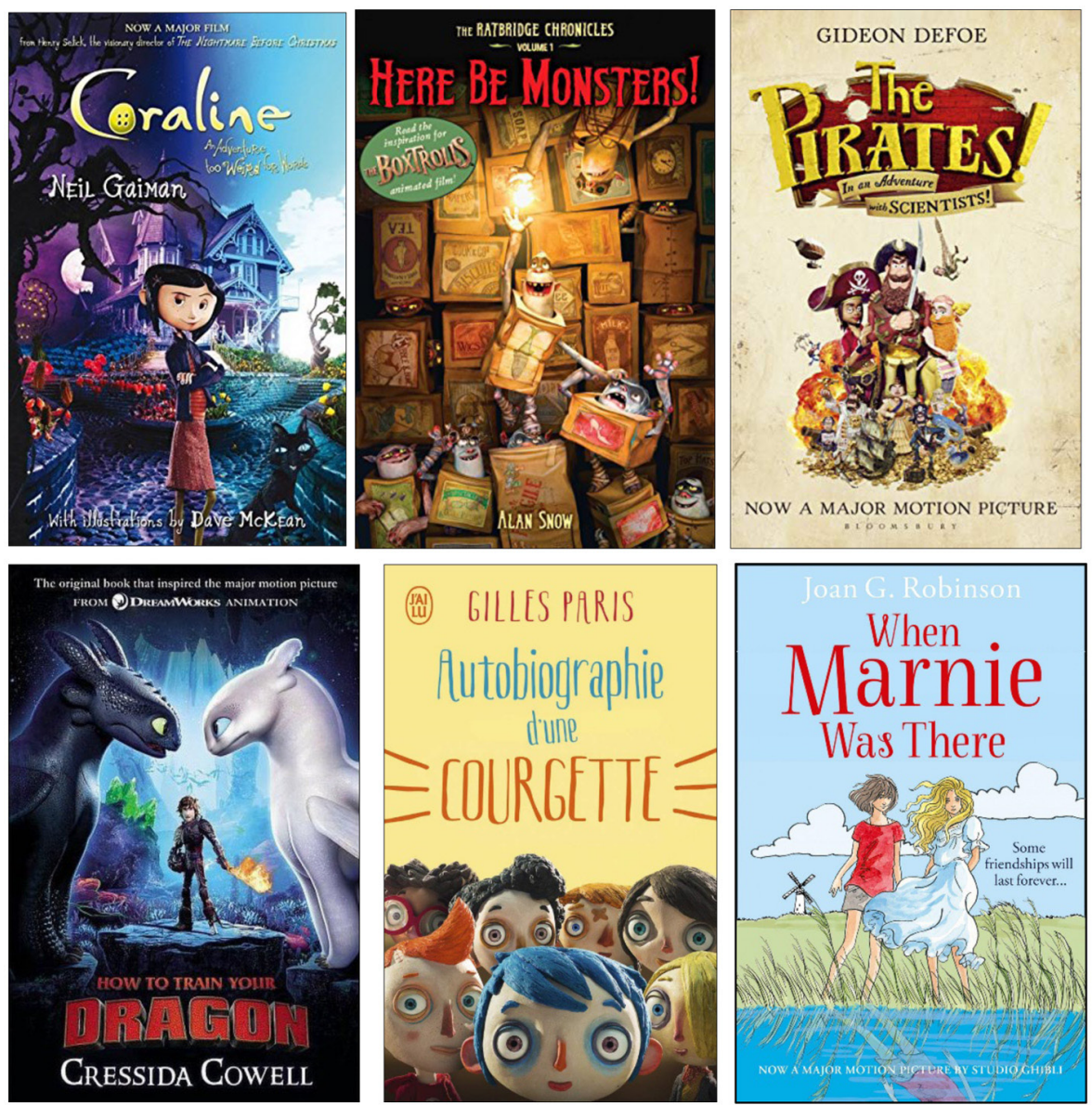

Imaxes 1, 2, 3, 4, 5, 6 [de esquerda a dereita e de arriba a abaixo]: cubertas da edición inglesa reeditadas de Coraline, Here Be Monsters!, The Pirates in an Adventure with Scientists, How to Train your Dragon, When Marnie Was There, e a cuberta da edición francesa de Autobiographie d'une courgette. 


\section{Conclusión}

Ao longo da realización do presente estudo foi posible chegar a unha serie de conclusións finais que permiten un entendemento máis axeitado do fenómeno da reescritura fílmica mediante técnicas de animación, así como a relevancia dos premios internacionais tanto para a obra premiada así como para os hipotextos literarios dos cales partiron.

Por unha parte, as porcentaxes obtidas demostran que arredor dun terzo das longametraxes animadas cuxa calidade estética e trama foron merecedoras do nomeamento a premios de relevancia internacional parten de obras literarias ou da banda deseñada. Polo tanto, literatura e cine seguen próximas neste eido e nútrense mutuamente, dándose tamén agora un proceso inverso de reescritura, de xeito que as películas dan lugar a novos produtos, algúns deles literarios. Por outra parte, a obtención dos dereitos de emisión destas películas polas actuais plataformas de streaming como Netflix ou HBO, e a recente creación de Disney+, revitaliza moitas destas historias literarias que foron levadas á gran pantalla dende mediados do século pasado.

Ademais, tamén é posible identificar unha clara tendencia á eliminación da dependencia constitutiva das reescrituras, de xeito que se constitúen como obras autónomas e totalmente afastadas da trama do hipotexto literario. Neste senso, refórzase a idea das películas como obras novas cuxo autor está composto polo equipo de produción, no cal destaca a figura do director e do guionista. Por esta razón, no caso dalgunha das reescrituras de obras contemporáneas, contan coa participación, nalgunha medida, do escritor.

En todo caso, pode observarse como a animación é unha técnica máis para a realización de películas que non é propia nin exclusiva das obras infantís, mais o público infantil e/ou familiar segue sendo o receptor obxectivo preferente. Así, algunhas delas contan con un dobre nivel de discurso que atrae e busca a complicidade con espectadores de distintas idades e, en todo caso, manteñen un nivel estético elevado e coidado, independentemente da utilización de técnicas dixitais ou outras como o stopmotion. 


\section{Referencias bibliográficas}

Deuchert, E., Adjamah, K. e Pauly K. (2005). For Oscar glory or Oscar money? Fournal of Cultural Economics, 29, 159-176. https://doi.org/10.1007/s10824-005$3338-6$

Equipo GLIFO (s.f.). Dicionario de Termos Literarios (DiTerLi). Xunta de Galicia e Centro Ramón Piñeiro para a Investigación en Humanidades. http://bernal.cirp. gal/ords/f? $\mathrm{p}=106: 50: \cdots: \ldots .:$

Genette, G. (1987). Seuils. Paris: Editions du Seuil.

Pilling, J. (2013). La animación se hace mayor. En R, Cueto, (Ed.), Animatopia. Los nuevos caminos del cine de animación (pp. 59-86). Donostia Zinemaldia.

Poveda Criado, M. A. (2015). Fuentes de financiación de la industria audiovisual española. Opción, 31 (2), 877-886. https://www.redalyc.org/exportarcita. oa? $\mathrm{id}=31045568048$

Sánchez Noriega, J. L. (2000). De la literatura al cine. Teoría y análisis de la adaptación. Barcelona: Ediciones Paidós Ibérica.

40 Tarrío Varela, A. (2013). Os premios literarios. En B. A. Roig Rechou, I. Soto López e M. Neira Rodríguez (coord.), Premios literarios e da ilustración na LIX (pp. 1534). Edicións Xerais de Galicia. 